\title{
JUSTIFYING THE NEED FOR IMPROVED HEALTH EDUCATION OF OBESE ADULT PATIENTS IN BULGARIA

\author{
Mima Nikolova $^{1}$, Silviya Kyuchukova ${ }^{2}$, Albena Andonova ${ }^{3}$
}

\begin{abstract}
Bulgaria is the second-fastest aging nation in Eastern Europe and fifth in the world. Older people are the largest and ever-growing group of people in health care. The most common diseases in this age group are circulatory, endocrine, digestive, musculature, neoplasms, and respiratory systems. Some of the main reasons for these diseases include an unhealthy diet, a sedentary lifestyle, and obesity.

One hundred twelve adult patients with chronic diseases were interviewed.

The aim of the study is to establish the awareness of older people about overweight-related problems. In order to increase their knowledge and improve their quality of life and independence, we prepared a training program (Table4).
\end{abstract}

UDC Classification: 614.2, DOI: https://doi.org/10.12955/pmp.v2.182

Keywords: elderly people, obesity, training, quality of life.

\section{Introduction}

With the continuous increase of life expectancy and persistent trends in declining birth rates in Bulgaria, the aging process continues. According to the data of the National Statistical Institute (NSI, 2020), at the end of 2018, people aged 65 and over were 1,493,119, or $21.3 \%$ of the country's population. The aging of the population has very serious social and economic consequences for the Bulgarian health system. The higher costs are not caused by the aging population itself but by the increase in the morbidity of elderly people. In people aged 65 and over, at first place in the structure are diseases of the circulatory system (24.1\%), followed by factors influencing the health status of the population, the contact with the health services (17.5\%), and the diseases of the digestive system (8.9\%). (Balkanska and Georgiev, 2008)

In most modern literature sources, it is reported that the phenomenon of polymorbidity is observed in this age group, which is a combination of two or more chronic diseases in one patient. Polymorbidity $(\mathrm{PM})$ is a new concept covering all diseases of the individual patient. PM is not just the amount of several nosological units, but the interaction between them with the formation of new disease status (Ministry of Health, 2011). This makes polymorbidity the most pressing problem of modern clinical geriatric practice. From the data analysis about the main health-demographic indicators is clear that currently Bulgaria, compared to the countries of the European Union, is facing a much more serious challenge related to the high level of overall mortality. It is formed mainly by the deaths of people over 65. Demographic projections show that, precisely because of the objective aging processes, the overall mortality rate in the country will remain high and unchanged until at least 2030. (Balkanska et al., 2008, Dimitrova,et al., 2009)

The health system is not effective in reducing preventable mortality, expressed in consistently high mortality from diseases such as cardiovascular disease, cancer, diabetes, and other non-communicable diseases. In fact, Bulgaria has the highest mortality from cerebrovascular disease (for example, stroke) in the EU and a very low survival rate for several cancer diseases. This indicates significant opportunities for optimizing health services, for example, by improving access to care and their quality and better prevention and better care coordination. (Dimitrova, et al., 2009)

The reasons for diseases that cause death or disability include unhealthy eating, sedentary lifestyle, and obesity. Obesity is most often due to several factors, mainly affecting lifestyle and diet, is a major health problem worldwide and is the leading preventable cause of death in the world, with increasing prevalence among adults and children. The authorities in this field believe that it is one of the most serious public health problems in the 21st century. (Balkanska, 2003, Blundell, 2014 )

\footnotetext{
${ }^{1}$ Trakya University, Faculty of Medicine, Department of "Health Care, Stara Zagora, Bulgaria, mima.nikolova@trakia-uni.bg

${ }^{2}$ Trakya University, Faculty of Medicine, Department of "Health Care, Stara Zagora, Bulgaria, silviya.kyuchukova@trakia-uni.bg

${ }^{3}$ Trakya University, Faculty of Medicine, Department of "Health Care, Stara Zagora, Bulgaria, albena.andonova@trakia-uni.bg
} 
In some European countries, half of the adult population is overweight or obese. According to the World Health Organization, $62 \%$ of the population is overweight - much more than the average level in the world, 39\%. Obesity increases the likelihood of various diseases, in particular cardiovascular disease, type 2 diabetes, obstructive sleep apnea, some cancer diseases, and diseases of the musculoskeletal system. The main treatment for obesity consists of diet and exercise. (Dimitrova et al., 2009, Dimova et al., 2019, Fujioka, 2015.)

Age-appropriate diets and age-appropriate physical activity are effective in dealing with excessive adipose tissue accumulation. Information on healthy eating will provide an opportunity to learn the rules of proper nutrition and their application in daily life.

Healthy eating is a guarantee of health, prevention of the development of deficiencies and deficits, but it also reduces the risk of developing a number of diseases and other health problems. (Council of Ministers, 2012, Garvey WT et al., 2014.)

\section{Methods of study}

- Documentary method for data collection and analysis of various documentary sources

- Sociological method - a survey of the opinions, attitudes, assessments of respondents on the studied problems

- Statistical methods - for analysis and interpretation of the data in order to reveal the nature of the observed phenomena and their dependence. They are used for the statistical presentation of the results

- Frequency analysis of qualitative variables - for calculating the absolute and relative frequencies $(\%)$

- Graphic analysis to illustrate the observed processes.

The study aims to establish the awareness of older people about weight problems and to examine its relationship to health

For achieving this goal, the following tasks have been performed:

1. Self-assessment of health status.

2. Presence of chronic disease.

3. Distribution of respondents by body weight.

4. The opinion of patients about the importance of the relationship between obesity and their health was studied and analyzed.

5. The readiness of the surveyed people to increase their awareness related to obesity was established

6. Prepare a training program.

7. Observe the participants' willingness to change their eating habits, improving their everyday physical activity, and their preferences of how to do that.

8. Self-assessment of health status after the end of the training.

\section{Results}

\begin{tabular}{|l|l|c|c|c|}
\hline \multicolumn{5}{|c|}{ Table 1: Presence of a chronic disease or health problem by age groups } \\
\hline $\begin{array}{c}\text { Prevalence of chronic } \\
\text { diseases }\end{array}$ & $\begin{array}{c}\text { Chronic consequences of } \\
\text { myocardial infarction }\end{array}$ & $\begin{array}{c}\text { Ischemic heart } \\
\text { disease }\end{array}$ & Hypertension \\
\hline $65-70$ & $7-41.1 \%$ & $2-11.8 \%$ & $9-53 \%$ \\
\hline $71-75$ & $15-71.4 \%$ & $4-19 \%$ & $10-47.6 \%$ \\
\hline $76-80$ & $14-22.2 \%$ & $17-27 \%$ & $42-66.7 \%$ \\
\hline $80+$ & $5-45.4 \%$ & $5-45.5 \%$ & $4-36.4 \%$ \\
\hline \multicolumn{4}{|l}{} \\
\hline
\end{tabular}

We surveyed 112 patients over the age of 65 in total, divided into the following age ranges: $65-70-18$ patients, $71-75-29$ patients, $76-80-73$ patients, 80 and more -9 patients.

We found that more than half $(76.8 \%)$ of the respondents rate their health status as satisfactory, bad, and very bad. Only $23.2 \%$ answered that their status is good or very good. Table 2 shows the answers for the self-assessment of the status by age group.

BMI (Body Mass Index) was calculated for all patients, the results are presented in Table 3 . The highest percentage of obesity was found in $19.7 \%$ of patients in the age group of $76-80,80$ and older $-18.6 \%$, $71-75-9.5 \%$. The lowest percentage of obesity -4.6 is in $65-70$-year-old. The overweight in 80 yearsold is $45.8 \%$, in $76-80$ years-old $-44.9 \%$, in $71-75$ years-old $-34.1 \%$ and $16.3 \%$ in $65-70$ years-old. 


\begin{tabular}{|c|c|c|c|}
\hline Age & $65-70$ & $71-75$ & $76-80$ \\
\hline Very good & 3 & 3 & 6 \\
\hline Good & 4 & 2 & 8 \\
\hline Satisfactory & 5 & 7 & 15 \\
\hline $\mathrm{Bad}$ & 3 & 4 & 21 \\
\hline
\end{tabular}

\begin{tabular}{|c|c|c|c|}
\hline \\
\hline \multicolumn{4}{|l|}{\begin{tabular}{c|c|c|} 
Table 3: BMI \\
BMI
\end{tabular}} \\
\hline & & $65-70$ & $71-75$ \\
\hline Weight below normal (under 18.5) & 2.2 & 5.9 & 3.4 \\
\hline Normal body weight (18.5-24.99) & 43.8 & 73.3 & 53.0 \\
\hline Overweight (25.00-29.99) & 39.2 & 16.3 & 34.1 \\
\hline
\end{tabular}

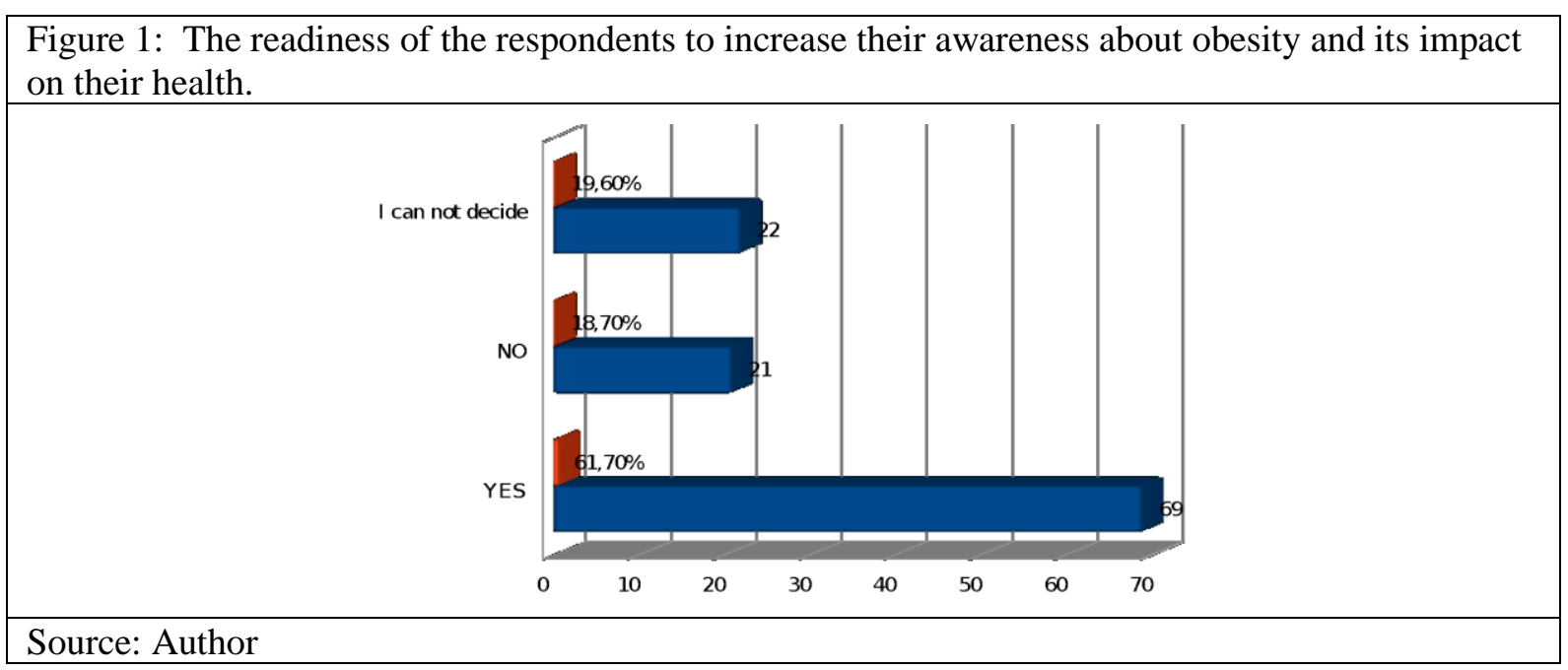

Fig. 1 provides information about the readiness of the respondents to increase their awareness of obesity and its impact on their health.

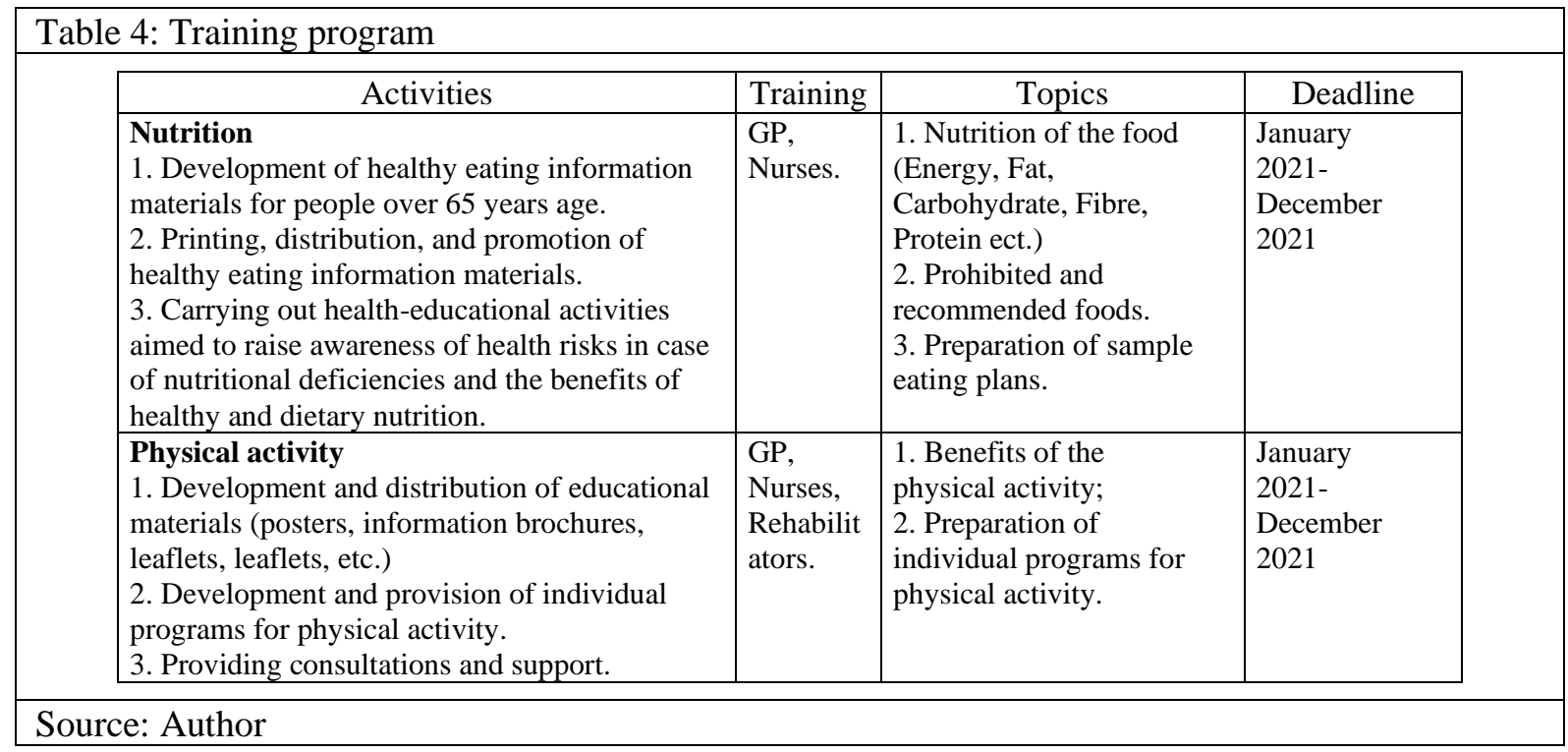

Willingness to raise awareness of obesity -69 or $61.7 \%$ of the respondents definitely wanted to raise their awareness of obesity, 22 of the respondents (19.6\%) could not judge, and only $21(18.7 \%)$ did not want to receive more information about obesity.

Training was provided to the 112 obese patients in small groups and individually. The training was on the topics indicated in Table 4 and in accordance with the individual characteristics of the patients 


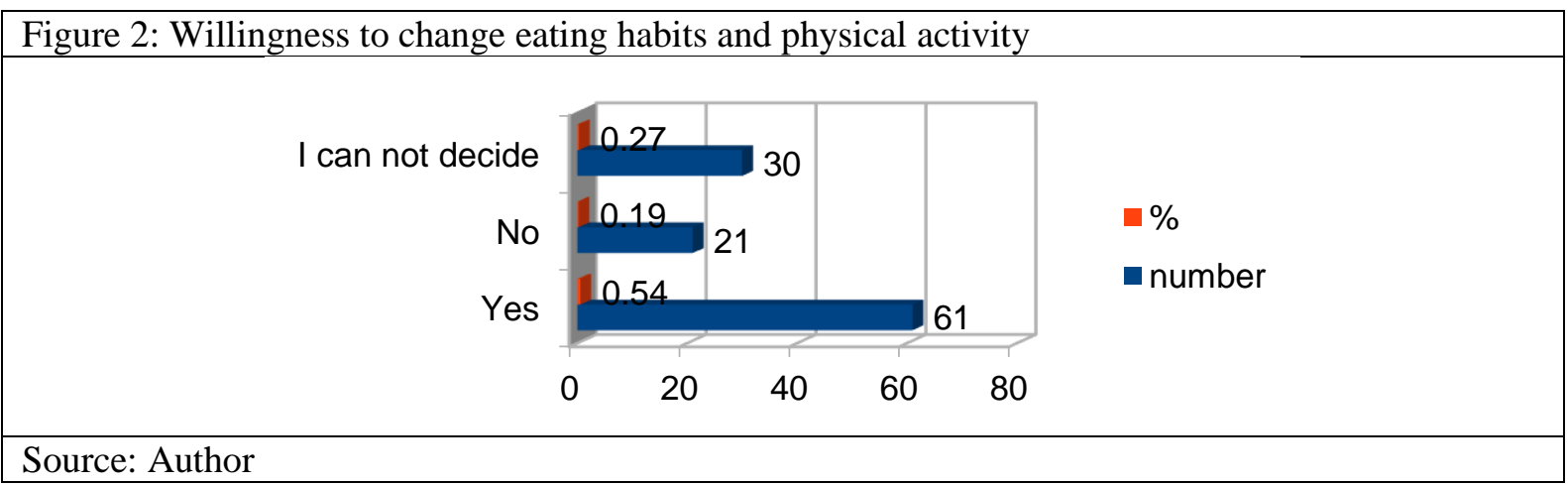

Fig. 2 preset the readiness of half (54\%) of the respondents to change their diet and physical activity, $27 \%$ are not convinced, and $19 \%$ do not want to.

\begin{tabular}{|c|c|c|c|}
\hline Age & $65-70$ & $71-75$ & $76-80$ \\
\hline Very good & 6 & 3 & 6 \\
\hline Good & 7 & 5 & 19 \\
\hline Satisfactory & 0 & 4 & 10 \\
\hline $\mathrm{Bad}$ & 2 & 4 & 15 \\
\hline
\end{tabular}

Table 5 presents the results of the self-assessment of the health status of the participants after the training. There is a significant improvement in self-esteem in all age groups.

\section{Conclusion}

There is a strong desire to raise awareness of obesity $-61.7 \%$ and only $18.7 \%$ do not have such a desire. After the course, the subjects reported an improved attitude and trust in the GP, nurses, and rehabilitators after the course. After thematically analyzing the stories of the respondents, we found positive changes in the attitudes, beliefs, and self-esteem of 112 elderly people. As evidenced by our study, overweight and obesity contribute greatly to the development of non-communicable diseases, reduce life expectancy, and adversely affect its quality. A training program for elderly people is developed in order to raise their awareness of obesity and its impact on health, a large percentage of chronically ill elderly people will be involved. Training elderly people will motivate and encourage them to lead a healthy lifestyle - proper nutrition and adequate physical activity. This lifestyle will improve their health and independence.

\section{References}

Balkanska, P.,(2003). The elderly man as a patient, Bulvest 2000, Sofia.

Balkanska, PA, S. Mladenova, N. Georgiev, (2008). Aging of the population and guidelines in the development of health care. Nursing, 30-33.

Balkanska PA, N. Georgiev, (2008). Priority guidelines of health care in the conditions of demographic transition, The interdisciplinary idea in action, ed. Acad. N. Manolov, ed. TEMPO, Sofia, 2008.

Blundell JA, Dulloo A, Salvador J et al., (2014). Beyond BMI - Phenotyping the Obesities. Obes Facts 2014;7:322-328.

Dimitrova N., M. Vukov, Z. Valerianova, (2009). Cancer incidence in Bulgaria, Bulgarian National Cancer Registry, Volume XX, Ed. Avis-24 Ltd., Sofia, 96.

Dimova, A., M. Rohova, S. Koeva, E. Atanasova, T. Kostadinova., (2019)."Bulgaria: Health System Review”, Health Systems in Transition, volume 14 (3), page $1-186$.

Fujioka K., (2015). Current and emerging medications for overweight or obesity in people with comorbidities. Diabetes, Obesity and Metabolism 2015;1

Garvey WT et al., (2014) American Association of Clinical Endocrinologists and American College of Endocrinology Position statement on the 2014 Advanced Framework for a new diagnosis of obesity as a chronic disease. Endocr Pract 2014; 20 (No.9)

Ministry of Health, (2011). Annual report on the state of health of citizens in 2010 and implementation of the National Health Strategy.

Council of Ministers, (2012). National concept for promoting the active life of the elderly (2012-2030)

(http://www.strategy.bg/StrategicDocuments/View.aspx?lang=bg-BG\&Id=764)

National Statistical Institute, (2020). Population demography, migration and forecasts

(http://www.nsi.bg/otrasal.php?otr=22\&a1=548\&a2=549\&a3=550\#cont) 